\title{
MODEL BIMBINGAN KELOMPOK BERBASIS HUMANISTIK UNTUK MENGUATKAN PENDIDIKAN KARAKTER MAHASISWA IKIP-PGRI PONTIANAK
}

\author{
Kamaruzzaman $^{(1)}$, Aliwanto ${ }^{(2)}$ \\ Program Studi Bimbingan dan Konseling \\ Fakultas Ilmu Pendidikan dan Ilmu Sosial \\ IKIP PGRI Pontianak \\ E-mail: oranecorby@gmail.com
}

\begin{abstract}
Abstrak
Penelitian ini dilakukan berdasarkan temuan empirik yang menunjukkan bahwa permasalahan karakter merupakan isu nasional yang menjadi perhatian bagi semua pihak. Oleh karena itu perlu dilakukan upaya atau strategi dalam menyikapi situasi tersebut, sehingga harapan karakter anak-anak bangsa sebagai masa depan bangsa dapat berkembang dengan baik. Tingkat karakter mahasiswa IKIP PGRI Pontianak berada pada kategori rendah, untuk itu perlu ditingkatkan. Penelitian ini bertujuan menghasilkan model bimbingan kelompok berbasis humanistik yang dapat meningkatkan karakter mahasiswa. Hasil penelitian ini menunjukkan bahwa model bimbingan kelompok berbasis humanistik efektif untuk menguatkan pendidikan karakter pada mahasiswa IKIP PGRI Pontianak. Faktanya pada uji hipotesis menunjukkan bahwa semua indikator karakter mahasiswa mengalami peningkatan yang signifikan setelah mendapatkan intervensi bimbingan kelompok berbasis humanistik. Hasil pengolahan data menunjukkan bahwa semua indikator karakter mahasiswa memperoleh nilai signifikansi atau mengalami peningkatan. Dengan demikian hipotesis kerja (Ha) yang berbunyi rata-rata karakter mahasiswa sebelum dan sesudah tindakan adalah mengalami peningkatan.
\end{abstract}

Kata kunci: karakter, model bimbingan kelompok berbasis humanistik

\begin{abstract}
This study is based on empirical findings that indicate that character issues are a national issue of concern to all parties. Therefore it is necessary to make efforts or strategies in addressing the situation, so hope the character of the nation's children as the future of the nation can develop well. Level character of IKIP PGRI Pontianak students are in the low category, for it needs to be improved. This study aims to produce a model based humanistic group guidance that can improve the character of students. The results of this study indicate that the model of humanistic-based group guidance is effective to strengthen character education in IKIP PGRI Pontianak students. The fact of the hypothesis test shows that all the indicators of student character experienced a significant increase after obtaining intervention based humanistic group guidance. The result of data processing shows that all the indicators of the character of the students get the value of significance or have increased. Thus the working hypothesis $(\mathrm{Ha})$ which reads the average character of students before and after the action is increased.
\end{abstract}

Key words: character, humanistic group based counseling model

Info Artikel

Diterima April 2018, disetujui Mei 2017, diterbitkan Juni 2018

Dipublikasikan Oleh: Program Studi Bimbingan dan Konseling 


\section{PENDAHULUAN}

Fenomena karakter merupakan isu nasional yang sangat prinsip menjadi permasalahan bangsa saat ini. Harian Kompas memberitakan bahwa berdasarkan indeks persepsi korupsi, yang dilaksanakan oleh lembaga survei Transparency International, Indonesia masih masuk jajaran negara-negara terkorup dengan menempati peringkat ke-118 dari 174 negara. (Kompas, 2012). Di harian yang sama, Badan Kehormatan DPR melaporkan ada 28 anggota dewan tersangkut masalah etika. Negeri ini berada dalam krisis multidimensional yang tak kunjung usai, kondisi diperburuk dengan krisis moral dan budi pekerti para pemimpin bangsa yang berimbas kepada generasi muda. Tawuran antar pelajar, perilaku seks bebas, penyalahgunaan narkoba, budaya tak tahu malu, tata nilai dan norma yang semakin merosot tidak hanya di perkotaan tapi sudah merambah ke pedesaan (Zuriah, 2007).

Dharma Kesuma Dkk (2011:2) menguraikan bahwa kondisi karakter yang rusak/hancur ditandai dengan maraknya seks bebas di kalangan remaja, peredaran narkoba, tawuran pelajar, peredaran foto dan video porno pada kalangan pelajar, dan korupsi yang merajarela di kalangan pejabat bangsa. Sebagai alternatif yang bersifat preventif, pendidikan diharapkan dapat mengembangkan kualitas generasi muda bangsa dalam berbagai aspek yang dapat memperkecil dan mengurangi penyebab berbagai masalah budaya dan karakter bangsa. Dalam nawacita yang diamanahkan pemerintah khususnya di bidang pendidikan diharapkan memberikan urgensi dalam merevolusi karakter anak bangsa. Upaya mengatasi kondisi tersebut diperlukan pemahaman dan langkah untuk membangun kembali karakter bangsa sesuai nilai-nilai Pancasila. Untuk merespon fenomena di atas maka diperlukan strategi preventif yang inovatif dalam menguatkan pendidikan karakter mahasiswa.

Berdasarkan pengamatan yang peneliti lakukan di IKIP-PGRI Pontianak ditemukan gejala-gejala yang menunjukkan rendahnya nilai karakter mahasiswa. Hal ini tampak pada perilaku maupun sikap saat mereka berkomunikasi antara satu dengan yang lain, terlebih pada dosen mereka. Permasalahan karakter dalam perilaku tersebut meliputi : keimanan (dimana sedikit sekali dari mereka yang memanfaatkan masjid kampus untuk melaksanakan ibadah) tanggung jawab (tidak sedikit dari mahasiswa yang lalai mengerjakan tugas yang diberikan), sopan santun (terlihat komunikasi antara mereka ke dosen), kurangnya kerja sama dalam mengerjakan tugas, selalu mengharapkan pekerjaan yang dibebankannya kepada orang lain, mengharapkan pekerjaan orang lain, saling buili baik secara langsung maupun tidak langsung seperti melalui media sosial. Permasalahan ini 
merupakan gejala yang ada dari beberapa mahasiswa di IKIP PGRI Pontianak. Jika dibiarkan secara belarut tentunya akan berbahaya bagi masa depan mereka, terlebih mereka sebagai calon-calon pendidik yang akan meneruskan ilmu dan karakter kepada anak-anak didik mereka. Fenomena yang diungkapkan tersebut, menunjukkan adanya kesenjangan yaitu ketidaksesuaian antara harapan dengan kenyataan. Permasalahan karakter perlu dipahami sedini mungkin untuk menganalisis strategi atau bantuan apa yang akan diberikan. Jika tidak direspon maka akan muncul generasi-generasi pemimpin penerus bangsa yang tidak memiliki karakter, seperti korupsi yang kian merajarela.

Bimbingan dan konseling memiliki peran penting dalam hal ini, bimbingan dan konseling merupakan bantuan yang diberikan kepada individu dalam memfasilitasi perkembangan mereka ke arah yang lebih baik. Berbagai layanan bimbingan dan konseling yang diberikan kepada individu yang mengalami masalah atau hambatan. Salah satunya adalah melalui layanan bimbingan kelompok. Tohirin (2007:170) menyebutkan bimbingan kelompok adalah suatu cara memberikan bantuan kepada individu melalui kegiatan kelompok. Kegiatan ini memberikan nuansa interaksi, komunikasi, antara anggota kelompok. Mereka saling mengerti, berbagi, dan memahani antar sesama anggota.
Berdasarkan kenyataan ini menjadi motivasi peneliti untuk mengembangkan bimbingan kelompok berbasis humanistik dalam menguatkan pendidikan karakter mahasiswa IKIP PGRI Pontianak. Humanistik penting dalam hal ini karena di dalam humanistik terdapat nilai-nilai yang merupakan potensi yang ada dan melekat di dalam diri manusia yang perlu dikembangkan. Menurut Corey (2009:54) nilai-nilai humanistik mencakup : (1) kesadaran diri, (2) kebebasan bertanggung jawab, (3) menciptakan hubungan yang bermakna, (4) usaha pencarian makna, (5) kecemasan, (6) kesadaran akan ketiadaan dan kematian.

Nilai-nilai tersebut merupakan konsep dasar dari pandangan humanistik yang ada pada setiap diri manusia, hal ini mengandung makna bahwa manusia memiliki kesadaran diri akan siapa dirinya, tanggung jawabnya serta kecemasan dalam dalam melakukan sesuatu. Humanistik memandang manusia secara keseluruhan dari potensi manusia itu sendiri. Luaran penelitian ini akan dikembangkan suatu model bimbingan kelompok dengan mengintegrasikan nilai-nilai humanistik ke dalam setiap tahapan pelaksanaannya sehingga menjadi suatu perbedaan dengan pelaksanaan bimbingan kelompok yang konvensional. 


\section{METODE PENELITIAN}

Penelitian ini adalah Research and Development yang dikembangkan Borg dan Gall (1989 :784), dengan langkah-langkah sebagai berikut : 1) meneliti dan mengumpulkan informasi tentang kebutuhan pengembangan, 2) merencanakan prototipe komponen yang akan dikembangkan termasuk mendefinisikan jenis keterampilan usaha yang akan dikembangkan, merumuskan tujuan, menentukan urutan kegiatan dan membuat skala pengukuran (instrumen penelitian), 3) mengembangkan prototipe awal untuk dijadikan model, 4) melakukan validasi model konseptual kepada para ahli atau praktisi. 5) melakukan ujicoba terbatas (tahap I) terhadap model awal, 6) merevisi model awal, berdasarkan hasil ujicoba dan analisis data, 7) melakukan ujicoba secara luas (tahap II), 8) melakukan revisi akhir atau penghalusan model, apabila peneliti dan pihak terkait menilai proses dan produk yang dihasilkan model belum memuaskan, dan 9) membuat laporan penelitian dan melakukan diseminasi kepada berbagai pihak.

Sembilan langkah tersebut, agar proses pelatihan menjadi lebih efektif dan efisien sesuai, didasarkan pada prinsip-prinsip dan langkah-langkah Borg dan Gall, dengan penyederhanaan langkah-langkah menjadi tiga tahap yaitu: 1) tahap research pendahuluan; 2) tahap pengembangan (development) model, 3) Model akhir. Penyedehanaan langkah tersebut dapat diuraikan sebagai berikut :

1. Penelitian

Pada tahap ini terdapat beberapa aktivitas utama yang perlu dilakukan yaitu studi literature,dan studi lapangan. Hasil studi dideskrifsikan dengan data faktual di lapangan.

2. Tahap Pengembangan

Berdasarkan pada masalah dan potensi yang diketahui dari hasil studi pendahuluan, maka langkah-langkah yaitu : perumusan format desain bimbingan kelompok berbasis humanistik, penyusunan/pengembangan

bimbingan kelompok berbasis humanistik, validasi ahli (ex pert judgement), evaluasi dan perbaikan, uji coba utama (experimental), evaluasi dan penyempurnaan.

3. Model Akhir

Setelah melewati tahap pengembangan yang diakhiri dengan evaluasi dan penyempurnaan, tahap berikutnya adalah tahap diseminasi dan sosialisasi.

HASIL PENELITIAN DAN PEMBAHASAN

\section{Hasil Penelitian}

Gambaran kecenderungan kenakalan remaja rata-rata berada pada kategori rendah dengan prosentase $42,25 \%$, yang terbagi dalam aspek yaitu : 1) Cinta Tuhan dan segenap ciptaannya mencapai 
$45,62 \%$, 2) Kemandirian dan Tanggung Jawab mencapai 44,5\%, 3) Kejujuran dan Amanah mencapai $43,33 \%$, 4) Hormat dan Santun mencapai 43,92 \%, 5) Darmawan, Suka Monolong, dan Kerja Sama mencapai 45,62\%, 6) Percaya diri dan kerja keras mencapai 44,5 \%, 7) Kepemimpinan dan Keadilan mencapai 44,58\%, 8) Baik dan Rendah Hati mencapai 51,25\%, 9) Toleransi, Kedamaian, dan Kesatuan mencapai $50 \%$.

\section{Grafik 1}

\section{Karakter Sebelum Diberikan Tindakan}

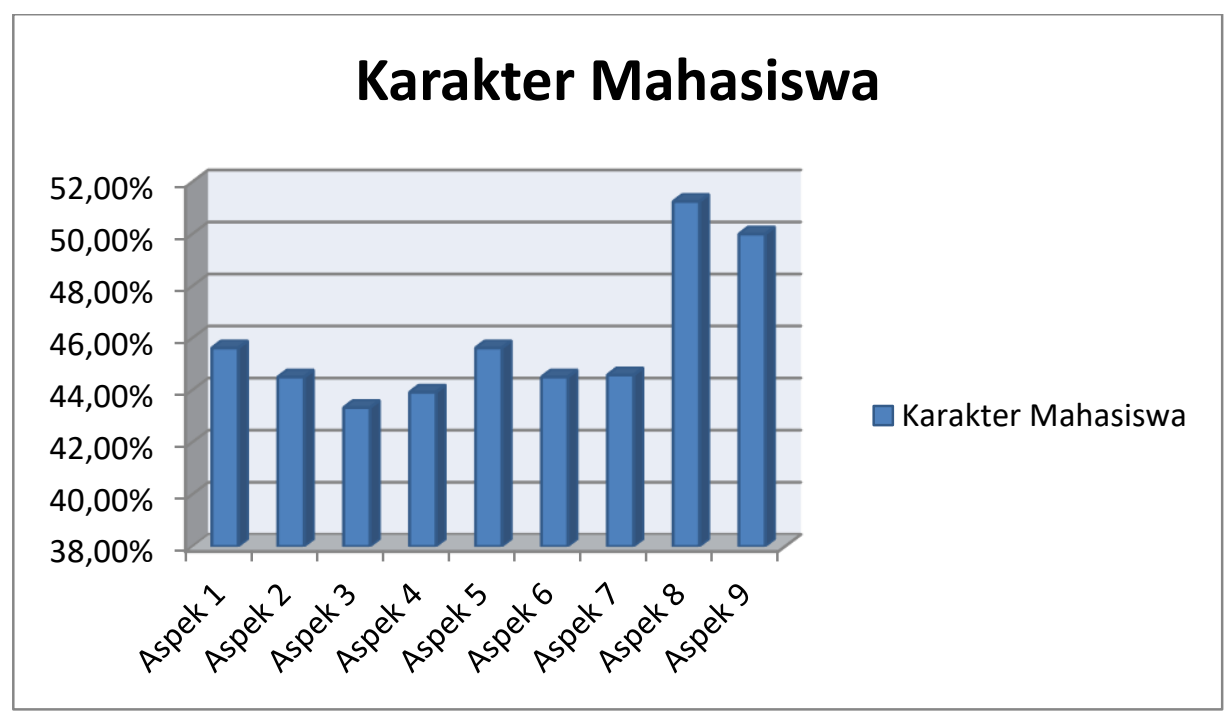

Dari hasil studi pendahuluan di atas, peneliti memandang perlu dikembangkan model bimbingan kelompok berbasis humanistik untuk menguatkan pendidikan karakter.

\section{PENGEMBANGAN}

\section{Model Bimbingan Kelompok \\ Berbasis Humanistik Untuk}

\section{Menguatkan Pendidikan Karakter}

Model hipotetik bimbingan kelompok berbasis humanistik untuk menguatkan pendidikan karakter terdiri dari : (1) rasional, (2) konsep kunci, (3) Visi dan Misi, (4) Tujuan,
(5) Materi, (6) peran dan fungsi konselor, (7) kualifikasi konselor, (8) anggota kelompok, (9) sifat topik dan suasana interaksi, (10) prosedur kerja bimbingan kelompok berbasis humanistik, (11) tahap-tahap bimbingan kelompok, (12) evaluasi dan tindak lanjut.

\section{Uji Kelayakan Model}

Uji kelayakan model dilakukan melalui penilaian pakar di bidang bimbingan dan konseling. Pakar yang dipilih dalam uji kelayakan ini adalah pakar-pakar yang berkompeten dalam 
bidang bimbingan dan konseling, yang berjumlah dua orang dan semuanya berlatar belakang S2, dua orang guru bimbingan konseling.

\section{Uji Lapangan}

Uji coba lapangan model bimbingan kelompok berbasis humanistik untuk menguatkan pendidikan karakter dilaksanakan sebanyak 8 kali pertemuan.

\section{Uji Keefektifan Model}

Uji keefektivan model layanan bimbingan kelompok berbasis humanistik untuk menguatkan pendidikan karakter dianalisis dengan statistik non-parametrik melalui perbandingan peningkatan hasil skor dan persentase sebelum dan setelah tindakan. Berdasarkan hasil persentase karakter mahasiswa yang sebelumnya $42,25 \%$ setelah diberikan tindakan mengalami peningkatan menjadi 64,1 $\%$. Dengan mengalami peningkatan sebesar 21,85 \%. Hal ini dapat diartikan bahwa model bimbingan kelompok berbasis humanistik efektif menguatkan pendidikan karakter mahasiswa.

\section{PEMBAHASAN PRODUK AKHIR}

Model bimbingan kelompok berbasis humanistik untuk menguatkan pendidikan karakter mahasiswa dikembangkan berdasarkan pada analisis studi pendahuluan yaitu data empiris kondisi objektif di lapangan (yaitu kondisi karakter mahasiswa, kondisi aktual bimbingan kelompok) dengan kaidah-kaidah bimbingan kelompok yang bersifat konseptual (yaitu kajian teoretik, hasil-hasil penelitian). Struktur model bimbingan kelompok berbasis humanistik untuk menguatkan karakter mahasiswa yang dikembangkan meliputi : (1) rasional; (2) tujuan; (3) asumsi; (4) sasaran layanan; (5) intervensi bimbingan kelompok berbasis pendekatan humanistik untuk menguatkan pendidikan karakter mahasiswa; (6) peranan guru bimbingan dan konseling dalam bimbingan kelompok berbasis humanistik untuk menguatkan pendidikan karakter; (7) anggota kelompok; (8) topik bimbingan kelompok berbasis humanistik mahasiswa; (9) tahaptahap bimbingan kelompok berbasis humanistik untuk menguatkan pendidikan karakter; (10) dinamika kelompok dalam bimbingan kelompok berbasis humanistik untuk meninguatkan pendidikan karakter mahasiswa; (11) evaluasi dan indikator keberhasilan bimbingan kelompok berbasis humanistik untuk menguatkan pendidikan karakter mahasiswa; (12) skenario pelaksanaan bimbingan kelompok berbasis humanistik untuk menguatkan pendidikan karakter.

Model bimbingan kelompok berbasis humanistik dikembangkan berdasarkan fenomena karakter sebagai isu nasional yang sangat prinsip menjadi permasalahan bangsa saat ini. Dharma Kesuma Dkk 
(2011:2) menguraikan bahwa kondisi karakter yang rusak/hancur ditandai dengan maraknya seks bebas di kalangan remaja, peredaran narkoba, tawuran pelajar, peredaran foto dan video porno pada kalangan pelajar, dan korupsi yang merajarela di kalangan pejabat bangsa. Sebagai alternatif yang bersifat preventif, pendidikan diharapkan dapat mengembangkan kualitas generasi muda bangsa dalam berbagai aspek yang dapat memperkecil dan mengurangi penyebab berbagai masalah budaya dan karakter bangsa. Dalam nawacita yang diamanahkan pemerintah khususnya di bidang pendidikan diharapkan memberikan urgensi dalam merevolusi karakter anak bangsa.

Upaya mengatasi kondisi tersebut diperlukan pemahaman dan langkah untuk membangun kembali karakter bangsa sesuai nilai-nilai Pancasila. Untuk merespon fenomena di atas maka diperlukan strategi preventif yang inovatif dalam menguatkan pendidikan karakter mahasiswa. Model bimbingan kelompok berbasis humanistik untuk menguatkan pendidikan karakter merupakan salah satu alternatif dalam mengatasi permasalahan tersebut.

\section{KESIMPULAN DAN SARAN}

\section{Kesimpulan}

Berdasarkan hasil penelitian dan pembahasannya yang dideskripsikan pada bab sebelumnya, maka dapat ditarik beberapa kesimpulan peneltian sebagai berikut:

1. Gambaran karakter mahasiswa IKIP PGRI Pontianak rata-rata berada pada kategori rendah. Mahasiswa belum sepenuhnya menjalankan nilai-nilai karakter yang diharapkan seperti : Cinta Tuhan dan segenap ciptaan-Nya, Kemandirian dan tanggung jawab, Kejujuran/amanah, Hormat dan santun, Dermawan, suka menolong, dan kerja sama, Percaya diri dan pekerja keras, Kepemimpinan dan keadilan, Baik dan rendah hati, Toleransi, kedamaian, dan kesatuan.

2. Rumusan model bimbingan kelompok berbasis humanistik terdiri dari 8 komponen diantaranya : (1) rasional, (2) tujuan, (3) manfaat, (4) prinsip pelaksanaan, (5) target intervensi, (6) kompetensi konselor, (7) prosedur pelaksanaan dan (8) evaluasi dan indikator keberhasilan. Kelayakan model tersebut telah divalidasi oleh 2 pakar bimbingan dan konseling yaitu pembimbing serta 2 praktisi/guru bimbingan dan konseling. Hasil uji kelayakan menunjukan bahwa model yang dirancang layak untuk diimplementasikan di lapangan.

3. Model layanan bimbingan kelompok berbasis humnistik efektif dapat menguatkan pendidikan karakter pada semua indikator yang meliputi : (1) Cinta 
Tuhan dan segenap ciptaan-Nya, (2) Kemandirian dan tanggung jawab, (3) Kejujuran/amanah, (4) Hormat dan santun,

Dermawan, suka menolong, dan kerja sama, (6) Percaya diri dan pekerja keras, (7) Kepemimpinan dan keadilan, (8) Baik dan rendah hati, (9) Toleransi, kedamaian, dan kesatuan.

4. kesimpulan ini didasarkan pada perbedaan skor evaluasi awal dan evaluasi akhir, dimana ada peningkatan skala psikologis karakter mahasiswa sebelum dan setelah diberi layanan bimbingan kelompok berbasis humanistik.

\section{Saran}

Berdasarkan simpulan hasil penelitian, maka beberapa saran yang dapat diberikan antara lain :

1. Bagi Mahasiswa

Karakter merupakan aspek
yang sangat penting dalam
kehidupan manusia, memiliki
karakter yang baik akan
memudahkan mahasiswa dalam
berinteraksi dan beradaptasi
dimanapun ia berada dan
memudahkan mahasiswa dalam
meraih kesuksesann.

2. Bagi pengembangan model selanjutnya

a. Peneliti (lanjutan) yang akan melakukan kajian yang sama diharapkan mengkaji lebih dalam mengenai analisis humanistik, agar penjabarannya lebih komprehensif.

b. Uji coba model tidak hanya dilaksanakan di unggulan salah satu perguruan tinggi atau sekolah, sehingga bisa dipastikan secara lebih objektif apakah model layanan bimbingan kelompok berbasis humanistik efektif apabila diberikan kepada mahasiswa dari perguruan tinggi atau sekolah lain (bukan unggulan).

\section{DAFTAR PUSTAKA}

Borg, Walter R. And Gall, Meredith D. 1993. Educational Reseach : An Introduction. New York and London; Longman

Corey (2009) Teori dan Praktik Pendekatan Konseling dan Psikoterapi. Jakarta : Rineka Cipta

Dharma Kesuma Dkk (2011) Pendidikan Karakter. Bandung : PT. Remaja Rosdakarya

Tohirin (2007) Bimbingan dan Konseling di Sekolah dan Madrasah. Jakarta : PT Raja Gravindo Persada

Zuriah (2007) Pendidikan Moral dan Budi Pekerti Dalam perspektif Perubahan. Jakarta : Bumi Aksara. 